\title{
Spatiotemporal Changes in Active Layer Thickness under Contemporary and Projected Climate in the Northern Hemisphere
}

\author{
Xiaoqing Peng, ${ }^{\text {a }}$ TinguUn Zhang, ${ }^{\text {a }}$ Oliver W. Frauenfeld, ${ }^{\mathrm{b}}$ Kang Wang, ${ }^{\mathrm{c}}$ \\ Dongliang LuO, ${ }^{\mathrm{d}}$ Bin CAO, ${ }^{\mathrm{a}}$ HAng Su, ${ }^{\mathrm{a}}$ HuiJun Jin, ${ }^{\mathrm{d}}$ AND QingBai Wu ${ }^{\mathrm{d}}$ \\ ${ }^{a}$ Key Laboratory of Western China's Environmental Systems (Ministry of Education), College of Earth and \\ Environmental Sciences, Lanzhou University, Lanzhou, China \\ ${ }^{\mathrm{b}}$ Department of Geography, Texas A\&M University, College Station, Texas \\ ${ }^{\mathrm{c}}$ Institute of Arctic and Alpine Research, University of Colorado Boulder, Boulder, Colorado \\ ${ }^{\mathrm{d}}$ State Key Laboratory of Frozen Soil Engineering, Northwest Institute of Eco-Environment and Resources, \\ Chinese Academy of Sciences, Lanzhou, China
}

(Manuscript received 6 October 2016, in final form 29 September 2017)

\begin{abstract}
Variability of active layer thickness (ALT) in permafrost regions is critical for assessments of climate change, water resources, and engineering applications. Detailed knowledge of ALT variations is also important for studies on ecosystem, hydrological, and geomorphological processes in cold regions. The primary objective of this study is therefore to provide a comprehensive 1971-2000 climatology of ALT and its changes across the entire Northern Hemisphere from 1850 through 2100. To accomplish this, in situ observations, the Stefan solution based on a thawing index, and the edaphic factor ( $E$ factor) are employed to calculate ALT. The thawing index is derived from (i) the multimodel ensemble mean of 16 models from phase 5 of the Coupled Model Intercomparison Project (CMIP5) over 1850-2005, (ii) three representative concentration pathways (RCP2.6, RCP4.5, and RCP8.5) for 2006-2100, and (iii) Climatic Research Unit (CRU) gridded observations for 1901-2014. The results show significant spatial variability in in situ ALT that generally ranges from 40 to $320 \mathrm{~cm}$, with some extreme values of $900 \mathrm{~cm}$ in the Alps. The differences in the ALT climatology between the three RCPs and the historical experiments ranged from 0 to $200 \mathrm{~cm}$. The biggest increases, of 120-200 cm, are on the Qinghai-Tibetan Plateau, while the smallest increases of less than $20 \mathrm{~cm}$ are in Alaska. Averaged over all permafrost regions, mean ALT from CMIP5 increased significantly at $0.57 \pm 0.04 \mathrm{~cm} \mathrm{decade}^{-1}$ during 1850-2005, while 2006-2100 projections show ALT increases of $0.77 \pm$ $0.08 \mathrm{~cm} \mathrm{decade}^{-1}$ for RCP2.6, $2.56 \pm 0.07 \mathrm{~cm} \mathrm{decade}^{-1}$ for RCP4.5, and $6.51 \pm 0.07 \mathrm{~cm} \mathrm{decade}^{-1}$ for RCP8.5.
\end{abstract}

\section{Introduction}

The combined land and ocean surface air temperatures increased $0.85^{\circ} \mathrm{C}$ from 1880 to 2012 (IPCC 2013). Considering the land surface air temperature changes alone, there has been an increase of $0.75^{\circ} \mathrm{C}$ between 1906 and 2005, which is most likely caused by the rapid rise in anthropogenic greenhouse gas concentrations in the atmosphere (Wang et al. 2011; Betts et al. 2016). Compared to the global mean, the rate and magnitude of temperature rise were much greater in high-latitude (Rothrock et al. 1999; Serreze et al. 2000; Symon et al. 2004; Chapin et al. 2005; Hinzman et al. 2005; Screen and Simmonds 2010; Jeong et al. 2012) and high-altitude regions (Pepin et al. 2015; Guo and Wang 2016).

\footnotetext{
Corresponding author: Tingjun Zhang, tjzhang@lzu.edu.cn
}

This temperature rise has resulted in worldwide permafrost degradation, including an increase in active layer thickness (ALT) (Frauenfeld et al. 2004; Zhao et al. 2010; Kaverin et al. 2012; Shiklomanov et al. 2012; Vaughan et al. 2013; Blunden and Arndt 2016; Luo et al. 2016; Wu et al. 2016). These ALT changes in permafrost regions can subsequently affect geomorphic processes, hydrologic processes, land cover and vegetation, infrastructure, and the sustainability of northern communities. Hazards associated with increases in ALT have important impacts on human activities (Shroder et al. 2014). In some areas, permafrost contains vast amounts of carbon and a large fraction is localized in the active layer (Mu et al. 2015; Schädel et al. 2016). Rising air temperatures can lead to ground warming and thickening of the active layer, which can result in previously frozen organic carbon becoming available for mineralization, 
elevating greenhouse gas concentrations if released to the atmosphere (Mu et al. 2016). Hydrological processes are similarly affected, such that ALT influences soil water storage and partitioning of surface water (Velicogna et al. 2012), as well as atmospheric moisture and precipitation (Ford and Frauenfeld 2016).

ALT is an important indicator of climate change in permafrost regions. Previous studies have developed several ground-based measurement methods to determine ALT at the point scale by using mechanical probing, thaw tubes, and ground temperature measured in boreholes (Romanovsky and Osterkamp 1995; Zhang et al. 1997, 2005; Brown et al. 2000; Hinkel et al. 2003; Smith et al. 2010; Zhao et al.2010). At the regional scale, some indirect measurements of ALT have been developed using, for example, remote sensing and modeling techniques (Goodrich 1978; Nelson and Outcalt 1987; Anisimov et al. 1997, 2002, 2007; Shiklomanov and Nelson 2002; Oelke et al. 2004, 2007; Liu et al. 2012; Arzhanov et al. 2013; Koven et al. 2013).

Changes in ALT have been reported at regional, hemispheric, and global scales (IPCC 2013). Significant increases in ALT have been reported in Russia (Frauenfeld et al. 2004; Zhang et al. 2005; Kaverin et al. 2012; Streletskiy et al. 2015), central and eastern Canada (Smith et al. 2010), central Asia (Zhao et al. 2010), and the Qinghai-Tibetan Plateau (Oelke and Zhang 2007; Wu and Zhang 2010; Pang et al. 2012; Wu et al. 2012, 2015). However, ALT in northern Alaska and western Canada shows little or no changes in recent decades (Streletskiy et al. 2008; Smith et al. 2009). The interactions between ALT and its driving factors are thus complex and depend on many interrelated physical processes. Climatic factors play a dominant role in accounting for the spatial and temporal variability of ALT at all scales (Streletskiy et al. 2008; Park et al. 2013, 2015), but nonclimatic factors such as vegetation cover, soil properties, and environmental factors are also critical (Jafarov et al. 2013; Mishra and Riley 2014; Gao et al. 2016). In most previous studies historical ALT changes were considered at the point scale, which cannot account for regional patterns of change. At the regional scale, simulations such as those from land surface models are the most common method for estimating ALT. However, in most cases, models assume the lower boundary to be at $3.5-5.0-\mathrm{m}$ soil depth with zero heat flux lower boundary conditions and constant thermal properties in the active layer (Lawrence and Slater 2005; Koven et al. 2013; Guo and Wang 2016). These simplifications result in a low accuracy of the ALT estimations (Lawrence and Slater 2005). Finite difference models for one-dimensional heat conduction with phase change have also been used to estimate ALT at the regional scale (Oelke et al. 2003, 2004), and Kudryavtsev's solution has been used to estimate ALT at the hemispheric scale (Anisimov et al. 1997). However, such numerical methods require data for climate forcing, vegetation, soil texture, soil moisture, snow, and other parameters. These variables are difficult to obtain, especially their dynamic changes at the hemisphere scale.

Given the important role of ALT changes in the climate system and the limitations and uncertainties of estimating ALT, it is important to properly evaluate and predict the spatiotemporal ALT changes at regional and hemispheric scales. The primary objective of this study is therefore to establish a 1971-2000 climatology of ALT and its changes for the entire Northern Hemisphere from 1850 through 2100 by combining in situ data and numerical modeling. To achieve this, we compiled in situ ALT data from 347 sites and derived the soil edaphic factor across the Northern Hemisphere. We then simulated ALT by using the Stefan solution with the air temperature thawing index estimated from various datasets and model outputs.

The unique and novel contribution of this study is our application of the most comprehensive database of 347 ALT observing stations, applying the Stefan solution with an improved edaphic factor methodology, and providing a long-term ( $251 \mathrm{yr}$ ) assessment of ALT variations across the Northern Hemisphere. These estimates of regional ALT changes are important indicators of contemporary and projected climate change in permafrost regions.

\section{Data and methods}

We use monthly mean air temperature, monthly precipitation, daily and monthly soil temperatures at multiple depths, in situ measured ALT, and a permafrost distribution map for the Northern Hemisphere. We derive a number of parameters, including the annual thawing index of air temperature and the edaphic factor, which will be used to estimate ALT in the permafrost regions of the Northern Hemisphere.

\section{a. Climatic Research Unit air temperature}

The Climatic Research Unit (CRU) version 3.23 time series dataset of surface air temperature is developed by the University of East Anglia (https://crudata.uea.ac.uk/ cru/data/hrg/cru_ts_3.23/). The monthly 1901-2014 $0.5^{\circ} \times 0.5^{\circ}$ latitude-longitude gridded temperatures are used to calculate the thawing index, which will be used as an input to estimate ALT.

\section{b. CMIP5 air temperature}

We used air temperature output from 16 models from phase 5 of the Coupled Model Intercomparison Project 
TABLE 1. Description of CMIP5 models used in this study. (Expansions of acronyms are available online at http://www.ametsoc.org/ PubsAcronymList.)

\begin{tabular}{|c|c|c|}
\hline Model & Institution and country & $\begin{array}{l}\text { Spatial gridpoint } \\
\text { resolution }(\text { lat } \times \text { lon })\end{array}$ \\
\hline CCSM4 & National Center for Atmospheric Research, United States & $192 \times 288$ \\
\hline CanESM2 & Canadian Centre for Climate Modelling and Analysis, Canada & $64 \times 128$ \\
\hline FIO-ESM & First Institute of Oceanography, State Oceanic Adminsitration, China & $64 \times 128$ \\
\hline GISS-E2-H & NASA Goddard Institute for Space Studies, United States & $90 \times 144$ \\
\hline GISS-E2-R & NASA Goddard Institute for Space Studies, United States & $90 \times 144$ \\
\hline IPSL-CM5A-LR & Institute Pierre-Simon Laplace, France & $96 \times 96$ \\
\hline IPSL-CM5A-MR & Institute Pierre-Simon Laplace, France & $143 \times 144$ \\
\hline MIROC-ESM-CHEM & $\begin{array}{l}\text { Japan Agency for Marine-Earth Science and Technology, } \\
\text { Atmosphere, Japan }\end{array}$ & $64 \times 128$ \\
\hline MIROC-ESM & $\begin{array}{l}\text { Japan Agency for Marine-Earth Science and Technology, } \\
\text { Atmosphere and Ocean Research Institute (The University of Tokyo), } \\
\text { and National Institute for Environmental Studies, Japan }\end{array}$ & $64 \times 128$ \\
\hline MIROC5 & $\begin{array}{l}\text { Atmosphere and Ocean Research Institute (The University of Tokyo), } \\
\text { National Institute for Environmental Studies, and Japan Agency for } \\
\text { Marine-Earth Science and Technology, Japan }\end{array}$ & $128 \times 256$ \\
\hline MPI-ESM-LR & Max Planck Institute for Meteorology, Germany & $96 \times 192$ \\
\hline MPI-ESM-MR & Max Planck Institute for Meteorology, Germany & $96 \times 192$ \\
\hline MRI-CGCM3 & Meteorological Research Institute, Japan & $160 \times 320$ \\
\hline NorESM1-M & Norwegian Climate Centre, Norway & $96 \times 144$ \\
\hline BCC_CSM1.1(m) & Beijing Climate Center, China Meteorological Administration, China & $160 \times 320$ \\
\hline BCC_CSM1.1 & Beijing Climate Center, China Meteorological Administration, China & $64 \times 128$ \\
\hline
\end{tabular}

(CMIP5), developed by various international research institutions (Table 1; https://esgf-node.llnl.gov/projects/ esgf-llnl/; Joetzjer et al. 2013). These model outputs employ different spatial resolutions but cover the same period from 1850 to 2100. Output from four CMIP5 experiments will be used: one historical experiment for 1850-2005 and three projections for 2006-2100 (Taylor et al. 2012). The three future scenarios are the representative concentration pathways (RCPs) developed for the Intergovernmental Panel on Climate Change (IPCC) Fifth Assessment Report (AR5), specifically RCP2.6, $\mathrm{RCP} 4.5$, and RCP8.5. Each of these four experiments is characterized by different radiative forcing. The historical experiment is forced with the observed atmospheric composition (Taylor et al. 2012). The CMIP5 model data were regridded to a common resolution of $0.5^{\circ} \times$ $0.5^{\circ}$ using a bilinear interpolation method (Chen and Frauenfeld 2014).

\section{c. Thawing index of air temperature}

The annual air temperature thawing index is defined as the sum of daily air temperatures for all days with temperatures above $0^{\circ} \mathrm{C}$ over a calendar year (1 January through 31 December). However, mean monthly air temperatures can also reliably be used to estimate the annual thawing index (Frauenfeld et al. 2007; Wu et al. 2011; Peng et al. 2016). Both monthly CRU air temperatures and the CMIP5 monthly air temperatures are used to calculate the annual thawing index of air temperature, which is subsequently used to estimate ALT.

\section{d. In situ $A L T$}

We assembled ALT observations from the Circumpolar Active Layer Monitoring Network (CALM) (Brown et al. 2000), the Global Terrestrial Network for Permafrost (GTN-P), meteorological stations in Russia including long-term records of soil temperature (Gilichinsky et al. 1998), and long-term field monitoring sites on the Qinghai-Tibetan Plateau (Table 2).

CALM currently comprises 240 sites across the Northern Hemisphere, mainly located in Arctic regions (Shiklomanov et al. 2012; Streletskiy et al. 2012). Except for some locations with missing data, 220 sites with ALT data and analogous information are available (https:// www.gwu.edu/ calm/data/data-links.html). CALM employs three primary methods of thaw depth measurements (Brown et al. 2000; Biskaborn et al. 2015; Fagan and Nelson 2017): 1) direct measurements by mechanical probing along grids or transects of various sizes, 2) thawtube observations, and 3) thaw depth inferred from ground temperature measurements. CALM also utilizes boreholes and soil temperature sites, where ALT is obtained from the temperature profile at single location. Different methods for measuring ALT are inevitable and the precise uncertainties among different methods vary, and are unknown. 
TABLE 2. Summary of the in situ ALT datasets.

\begin{tabular}{lccl}
\hline \hline \multicolumn{1}{c}{ Type } & Collected & Used & \multicolumn{1}{c}{ Methods } \\
\hline CALM & 240 & 220 & Thaw tube and soil temperature \\
GTN-P & 207 & 65 & Hourly, daily, and monthly soil temperature \\
Russia meteorological stations & 62 & 39 & Daily and monthly soil temperature \\
Own monitored sites & 23 & 23 & Daily soil temperature \\
\hline
\end{tabular}

The GTN-P dataset includes 21 sites with hourly soil temperature, 69 sites with daily data, and 117 sites with monthly soil temperature. All stations were classified as located on either permafrost or seasonally frozen ground based on soil temperature at each depth (Frauenfeld et al. 2004). ALT was computed by determining the annual maximum thaw depth of the $0^{\circ} \mathrm{C}$ isotherm in the soil temperature profile. Because some sites are not located on permafrost or contain missing data, 65 sites are retained for computing ALT in this study.

Long-term measurements of soil temperature at closely spaced intervals $(5-40 \mathrm{~cm})$ to depths of up to $320 \mathrm{~cm}$ at meteorological stations have been collected for many decades in the former Soviet Union (Gilichinsky et al. 1998; Frauenfeld et al. 2004; Zhang et al. 2005). There are 31 permafrost stations recording daily soil temperatures, with some records extending from the late 1950s and mid-1960s to 2006. There are also 31 stations on permafrost derived from monthly soil temperatures, and the record includes annual maximum thaw depths from 1930 to 1990. Comparing the location of the stations in these two datasets, 14 have both soil temperature and thaw depth observations. Because ALT calculated using daily soil temperatures is more accurate, we retain those ALT records. Altogether, there are 39 stations with ALT estimations from these two datasets.

We compiled additional ALT data from 10 sites on the Qinghai-Tibetan Plateau (Wu and Zhang 2010; Wu et al. 2015) and 13 sites from the Heihe River basin northeast of the Tibetan Plateau (Wang et al. 2015). Altogether, we have ALT data and information from 34 stations on the Qinghai-Tibetan Plateau.

By combining all available in situ ALT datasets, we are able to improve on the study by Luo et al. (2016), who compiled ALT observations from approximately 230 sites, to assemble observations from 347 locations across the Northern Hemisphere. To our knowledge, this represents the most comprehensive observational ALT dataset and is used as ground truth in this study.

\section{e. Methods}

To compare the edaphic factor derived from the different methods with observational and simulated ALT results, the mean percent error (MPE), mean bias error (MBE), and root-mean-square error (RMSE) are used:

$$
\begin{aligned}
\mathrm{MPE} & =\frac{1}{N} \sum_{i=1}^{N} \frac{H_{i e}-H_{i m}}{H_{i m}} \times 100, \\
\mathrm{MBE} & =\sum_{i=1}^{N}\left(H_{i e}-H_{i m}\right) / N, \text { and } \\
\mathrm{RMSE} & =\sqrt{\sum_{i=1}^{N}\left(H_{i e}-H_{i m}\right)^{2} / N,}
\end{aligned}
$$

where $H_{i e}$ and $H_{i m}$ are simulated and observed data, respectively, and $N$ is the sample size. To investigate the temporal variations and statistical characteristics of ALT, a simple linear tendency combined with least squares is used to quantify the trends.

\section{f. ALT calculated by the Stefan solution}

The approximate Stefan solution is widely used in calculating ALT in permafrost regions (Nelson and Outcalt 1987; Zhang et al. 1997; Shiklomanov and Nelson 2002; Zhang et al. 2005):

$$
\mathrm{ALT}=\sqrt{\frac{2 k_{t} n_{t} \mathrm{TI}}{P_{b} W L}} .
$$

In Eq. (4), $k_{t}$ is the thermal conductivity of the thawed soil $\left(\mathrm{W} \mathrm{m}^{-1}{ }^{\circ} \mathrm{C}^{-1}\right), n_{t}$ is the $n$ factor for the thawing season, reflecting the relationship between the air and surface freezing/thawing index, TI is the annual thawing index $\left({ }^{\circ} \mathrm{Cday}^{-1}\right), P_{b}$ is the soil bulk density $\left(\mathrm{kg} \mathrm{m}^{-3}\right), W$ is the soil water content by weight (dimensionless), and $L$ is the latent heat of fusion $\left(\mathrm{J} \mathrm{kg}^{-1}\right)$. This method requires parameters that are only available at few specific sites, but not at regional or hemispheric scales.

Here, we used the modified Stefan equation and simplified it (Zhang et al. 2005) to where Eq. (4) can be rewritten as

$$
\mathrm{ALT}=E \sqrt{\mathrm{TI}}
$$

where

$$
E=\sqrt{\frac{2 k_{t} n_{t}}{P_{b} W L}} .
$$


Therefore, $E$ is a catchall scaling parameter, which Nelson and Outcalt (1987) referred to as "the edaphic term" and we refer to it as the edaphic factor or $E$ factor.

\section{g. E factor}

Applying the concept of the edaphic factor would simplify the ALT estimation. However, the new challenge is to obtain reliable $E$-factor values because it is very difficult to obtain each parameter on the right-hand side of Eq. (6). From Eq. (5), $E$ can also be written as

$$
E=\mathrm{ALT} / \sqrt{\mathrm{TI}} .
$$

To apply Eq. (7), we can use in situ ALT and air thawing index from the same stations. Therefore, we calculated the $E$-factor values at each individual location based on the 347 in situ ALT measurements and thawing index from the corresponding CRU grid cell. The spatial distribution of the $E$ factor at the various sites ranges from 0 to greater than 18 across the permafrost regions of the Northern Hemisphere, with most being between 0 and 12 (Fig. 1). The $E$-factor standard deviation (STD) varies between 0.0 and approximately 1.4, with $58 \%$ of all sites having an STD of $0.0-0.3$ and only $12 \%$ of sites having an STD greater than 1.0. This indicates that the interannual variability of the $E$ factor is not very pronounced. Having relatively constant $E$ factors at most of the sites is helpful for projecting ALT changes into the future based on different scenarios. Provided that an appropriate gridded $E$-factor value can be calculated and combined with a gridded thawing index, the gridded ALT can be determined based on Eq. (5).

Most previous studies evaluated the spatial variability of the $E$ factor based on land-cover type (Zhang et al. 2005; Park et al. 2016) or ecoregion (Smith et al. 2009). To assess the most appropriate method for calculating the $E$ factor, we used several approaches. The spatial variability of the $E$ factor was evaluated by categorizing the values at individual locations based on their respective land-cover type. A global land-cover dataset at $0.05^{\circ}$ resolution is obtained from the Moderate Resolution Imaging Spectroradiometer (MODIS) International GeosphereBiosphere Programme (IGBP) classification system (https://lpdaac.usgs.gov/). Next, we derive the spatial $E$ factor based on soil type using the Harmonized World Soil Database (HWSD) version 1.2 (http://webarchive. iiasa.ac.at/Research/LUC/External-World-soil-database/ HTML/). We then use an inverse-distance weighting (IDW) method to estimate the spatial $E$-factor values, and also to derive the soil parameters' spatial variability (Robinson and Metternicht 2006). Kriging, a nonlinear method with an unbiased optimal estimator, is also used

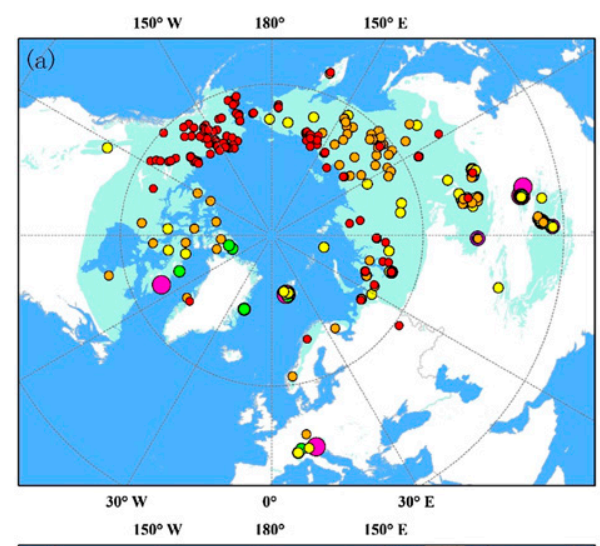

Edaphic Factor

- $0.0-3.0$

○ $3.0-6.0$

○ $6.0-9.0$

○ $9.0-12.0$

- $12.0-15.0$

- $15.0-18.0$

$>18.0$

1:70,000,000

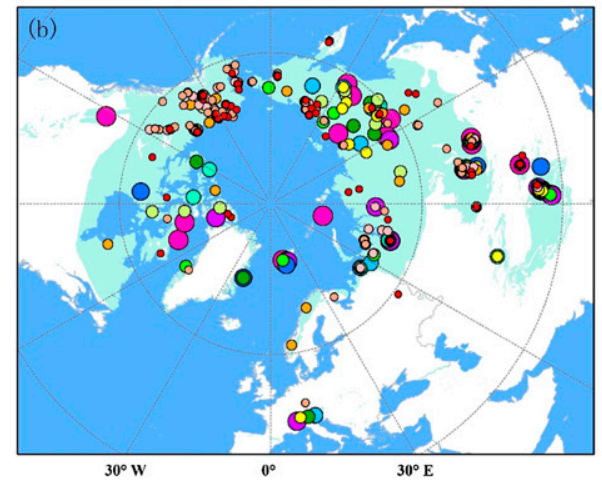

STD

- $\quad 0.0-0.1$

○ $0.1-0.2$

○ $0.2-0.3$

○ $0.3-0.1$

○ $0.4-0.5$

○ $0.5-0.6$

○ $0.6-0.7$

- $0.7-0.8$

○ $0.8-0.9$

○ $0.9-1.0$

1. $1.0-1.2$

( 1.21 .4

$>1.1$

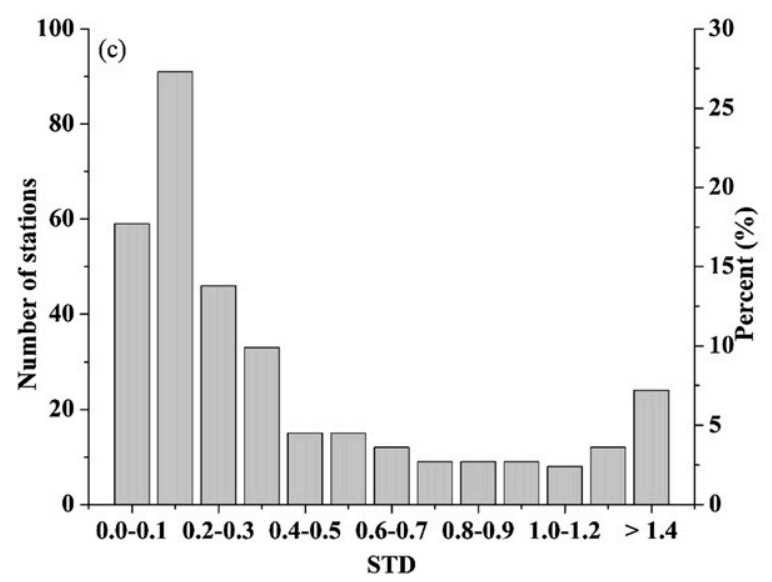

FIG. 1. Spatial distribution of edaphic factors across the sites: (a) mean $E$ factor, (b) the STD of the $E$ factor, and (c) distribution of STD.

to derive the spatial $E$-factor values (Gotway et al. 1996). Finally, a nonlinear radial basis function artificial neural network (RBFANN) method, which is widely used in simulating soil parameters (Dong et al. 2010), is also applied to estimate the spatial $E$-factor values. Table 3 summarizes these different estimates relative to observed $E$ factors. The best method for deriving the spatial $E$-factor value is kriging, because it has the smallest MPE of $14.1 \%$, MBE of -0.02 , and RMSE of 2.04 (Table 3). Thus, the spatial $E$-factor 
TABLE 3. The $E$ factor evaluation based on MPE, MBE, and RMSE for the different estimation methods.

\begin{tabular}{lccc}
\hline \hline Method & MPE (\%) & MBE & RMSE \\
\hline Land cover & 46.9 & -0.44 & 4.03 \\
Soil type & 50.4 & -0.39 & 4.30 \\
IDW & 29.9 & 0.79 & 3.19 \\
Kriging & 14.1 & -0.02 & 2.04 \\
RBFANN & 15.4 & -0.71 & 5.53 \\
\hline
\end{tabular}

values are gridded using the kriging method at the same spatial resolution as the CRU dataset (Fig. 2). The spatial variability of the gridded $E$ factor ranges from 1 to greater than 15, with its STD ranging between 0.0 and 1.5. The ratio between the STD and $E$ factor is less than $10 \%$. Therefore, we assume the $E$ factor has few to no interannual changes in this study. The $E$-factor values are applied to provide gridcell level ALT using thawing index estimates over both the CRU historical record and that of the CMIP5 model outputs.

\section{h. Permafrost map}

We use the International Permafrost Association (IPA) circum-Arctic map of permafrost and ground ice conditions (Brown et al. 1998; Zhang et al. 1999, 2003) to identify permafrost regions in the Northern Hemisphere. The regions for ALT estimation are limited within the permafrost boundaries as determined by the IPA map.

\section{Results}

\section{a. Historical ALT in the Northern Hemisphere}

\section{1) IN SITU ALT SPATIAL VARIABILITY}

Based on all in situ ALT measurements in the Northern Hemisphere (Fig. 3), ALT ranges from less than $40 \mathrm{~cm}$ in northern Alaska to more than $300 \mathrm{~cm}$ on the Mongolian and Qinghai-Tibetan Plateaus, with an extreme value of up to $900 \mathrm{~cm}$ over the Alps. The multiyear average ALT was less than $40 \mathrm{~cm}$ in continuous permafrost regions, and $40-80 \mathrm{~cm}$ in the discontinuous permafrost regions of Alaska. This is relatively shallower than other high-latitude regions. For the rest of North America, ALT ranged from 80 to $200 \mathrm{~cm}$ over continuous permafrost, and more than $240 \mathrm{~cm}$ in the sporadic and isolated permafrost regions of the Rocky Mountains. In Siberia east of $150^{\circ} \mathrm{E}$, ALT was up to $80 \mathrm{~cm}$, and ranges from 120 to $240 \mathrm{~cm}$ in the continuous permafrost regions from $120^{\circ}-150^{\circ} \mathrm{E}$. In western Siberia, ALT varies from about $80 \mathrm{~cm}$ to more than $240 \mathrm{~cm}$. On the Mongolian Plateau, ALT is

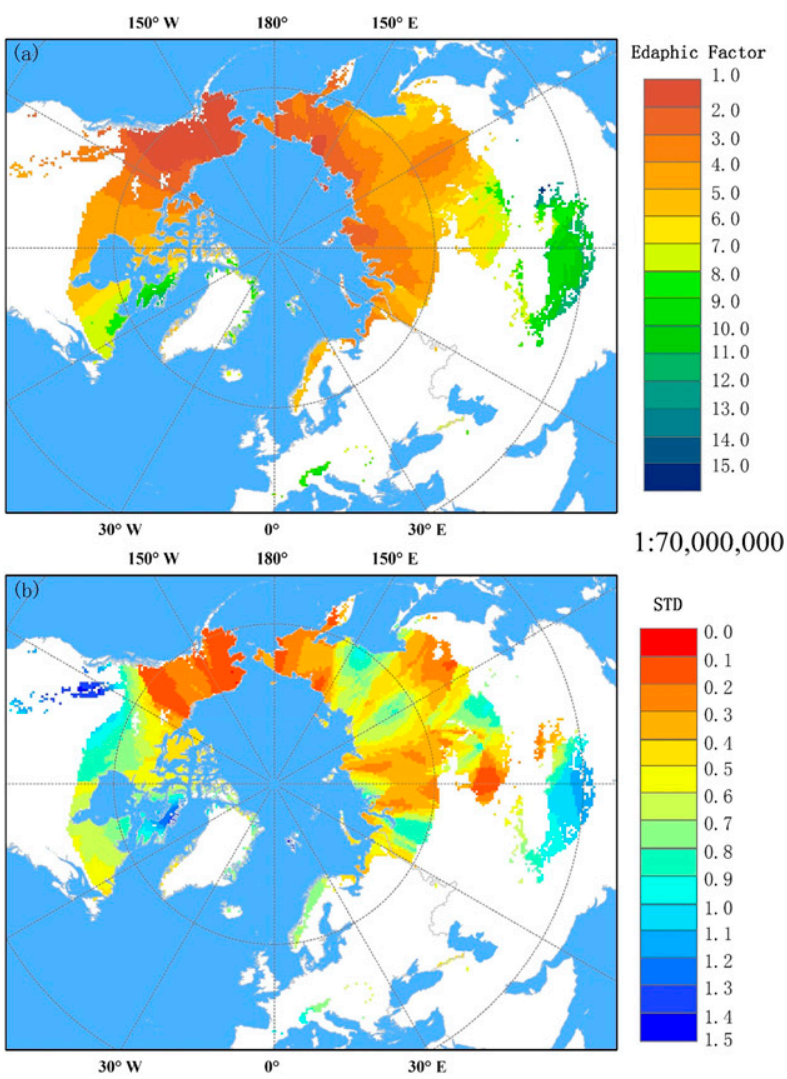

FIG. 2. Spatial distribution of (a) the $E$ factor and (b) its STD at the regional scale.

about $120 \mathrm{~cm}$ in continuous permafrost regions, and more than $320 \mathrm{~cm}$ in sporadic and isolated permafrost regions. Similarly, on the Qinghai-Tibetan Plateau, the ALT ranges from $120 \mathrm{~cm}$ to more than $320 \mathrm{~cm}$. The maximum ALT was located in the Alps, where it varies from 200 to $900 \mathrm{~cm}$ in sporadic and isolated permafrost regions. Luo et al. (2016) reported ALT to be $48 \mathrm{~cm}$ in Alaska, $93 \mathrm{~cm}$ in Canada, $60-92 \mathrm{~cm}$ in Russia, and $230 \mathrm{~cm}$ over the Tibetan Plateau. Given their different (1990-2015) analysis period and different datasets (only CALM), these values still generally correspond to our findings.

\section{2) ALT CLIMATOLOGY DERIVED FROM THAWING INDEX DURING THE HISTORICAL PERIOD}

Based on thawing index computed from the CRU dataset, from ensemble-averaged CMIP5 data during 1971-2000, and from spatially gridded $E$-factor values, we estimated ALT (Figs. 4a,b) over the Northern Hemisphere using Eq. (5). ALT of about $30 \mathrm{~cm}$ is found in Greenland. In northern Alaska, it varies between 30 and $60 \mathrm{~cm}$. For the rest of North America, between $180^{\circ}$ and $60^{\circ} \mathrm{W}$, the mean ALT varies from about $30 \mathrm{~cm}$ to more than $300 \mathrm{~cm}$. In Siberia, ALT varies from 60 to 


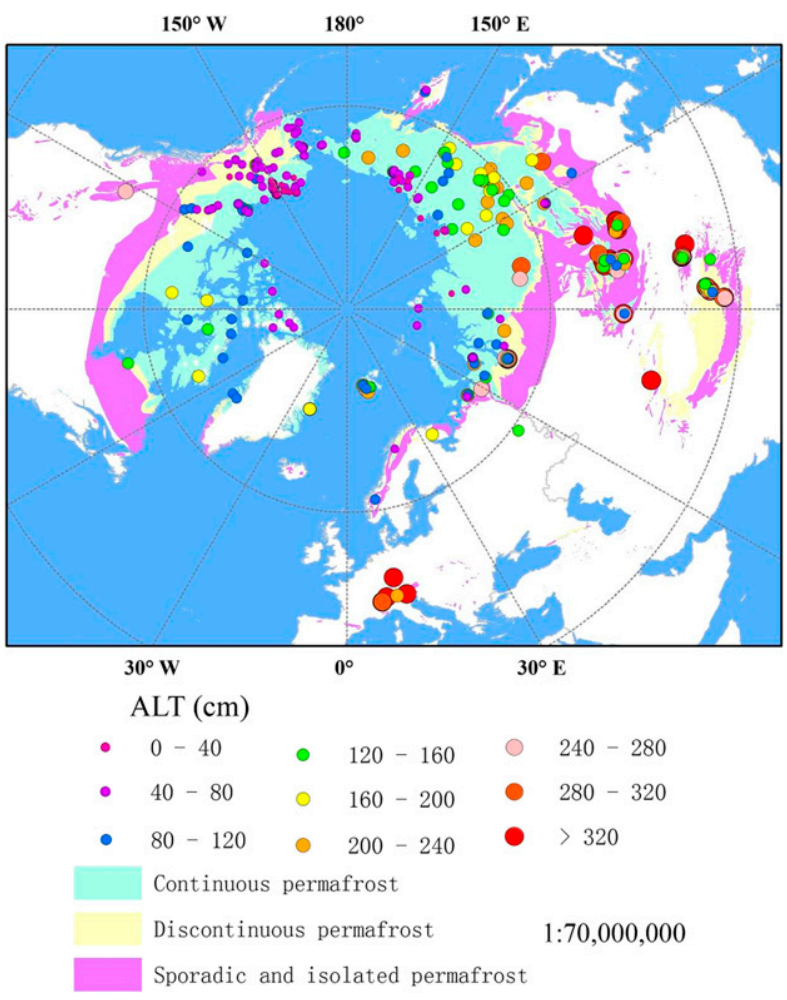

FIG. 3. Spatial distribution of multiyear average in situ ALT at each site across the Northern Hemisphere.

$250 \mathrm{~cm}$, and generally increases from east to west. On the Mongolian Plateau, ALT varies from 200 to $500 \mathrm{~cm}$. In northeastern China, ALT is generally $320 \mathrm{~cm}$ in most regions. On the Qinghai-Tibetan Plateau, ALT varies from 150 to $400 \mathrm{~cm}$, but it can be up to $650 \mathrm{~cm}$ in some regions. In the Alps and northern Europe, ALT varies from about $100 \mathrm{~cm}$ to greater than $300 \mathrm{~cm}$.
Spatial ALT patterns from the historical ensemble CMIP5 dataset are similar to that of the CRU data during 1971-2000 (Figs. 4a,b) but there are notable differences (Fig. 4c). A large negative bias (less than $-50 \mathrm{~cm}$ ) is located north of $60^{\circ} \mathrm{N}$ and in the Alps. The reason for this is likely that the thawing index derived from CMIP5 is underestimated in these regions compared to the CRU dataset, which is consistent with previous results (Knutson et al. 2013). Large positive differences (greater than $20 \mathrm{~cm}$ ) are evident on the Qinghai-Tibetan Plateau, which likely indicates that ALT derived from CMIP5 is overestimated relative to CRU. Previous research reported that surface air temperature is overestimated by CMIP5 on the Tibetan Plateau (Chen and Frauenfeld 2014).

ALT derived from both the CRU dataset and the ensemble-averaged CMIP5 output shows dramatic changes along different longitudinal and latitudinal gradients in the Northern Hemisphere (Fig. 5). Along the $65^{\circ} \mathrm{N}$ transect (Fig. 5a), ALT ranges from 17 to $250 \mathrm{~cm}$, with an average of $120 \mathrm{~cm}$. Along this transect, the shallower ALTs are mainly in Alaska and the eastern Siberian regions. Along the transect of $95^{\circ} \mathrm{E}$ (Fig. 5b), the mean ALT ranges from 360 to $600 \mathrm{~cm}$ near $30^{\circ} \mathrm{N}$ and then decreases, reaching a minimum of less than $100 \mathrm{~cm}$ around $34^{\circ} \mathrm{N}$. ALT increases northward and ranges from about 400 to $500 \mathrm{~cm}$ between $40^{\circ}$ and $44^{\circ} \mathrm{N}$. From $45^{\circ} \mathrm{N}$ poleward, the mean ALT decreases as latitude increases. This transect represents ALT variations from the high-altitude Tibetan Plateau, through the midlatitude Mongolian Plateau, ending with highlatitude Siberian regions in the Eastern Hemisphere. In the Western Hemisphere, we chose the $120^{\circ} \mathrm{W}$ transect (Fig. 5c), which shows that the mean ALT decreases

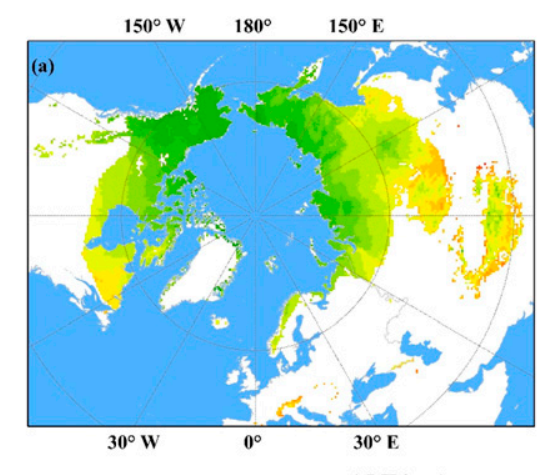

ALT(cm)
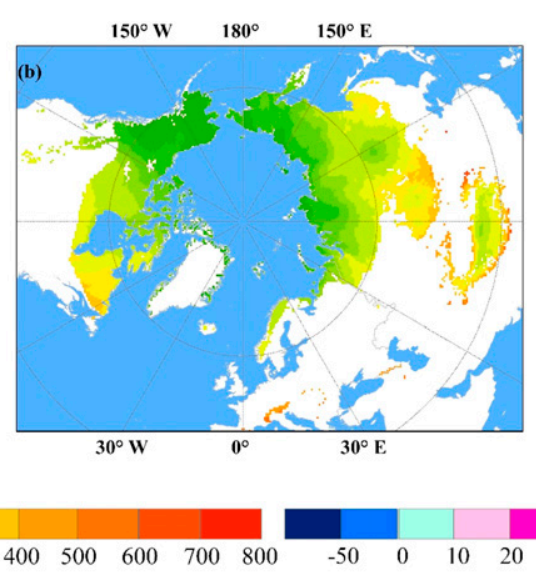

$1: 50,000,000$

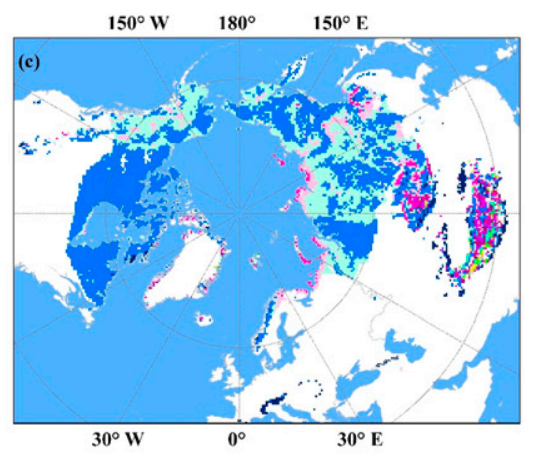

ALT Difference (cm)

$\begin{array}{llllllllllllllllllllllllllll}0 & 30 & 60 & 90 & 120 & 150 & 200 & 250 & 300 & 400 & 500 & 600 & 700 & 800 & -50 & 0 & 10 & 20 & 40 & 60 & 80 & 100 & 120 & 140 & 160 & 180 & 200\end{array}$

FIG. 4. Spatial distribution and differences of 30-yr-average ALT in permafrost regions across Northern Hemisphere, showing (a) values based on CRU data for 1971-2000, (b) the ensemble mean of 16 CMIP5 models for the historical experiment for 1971-2000, and (c) the ALT difference between CRU and CMIP5 for 1971-2000. 


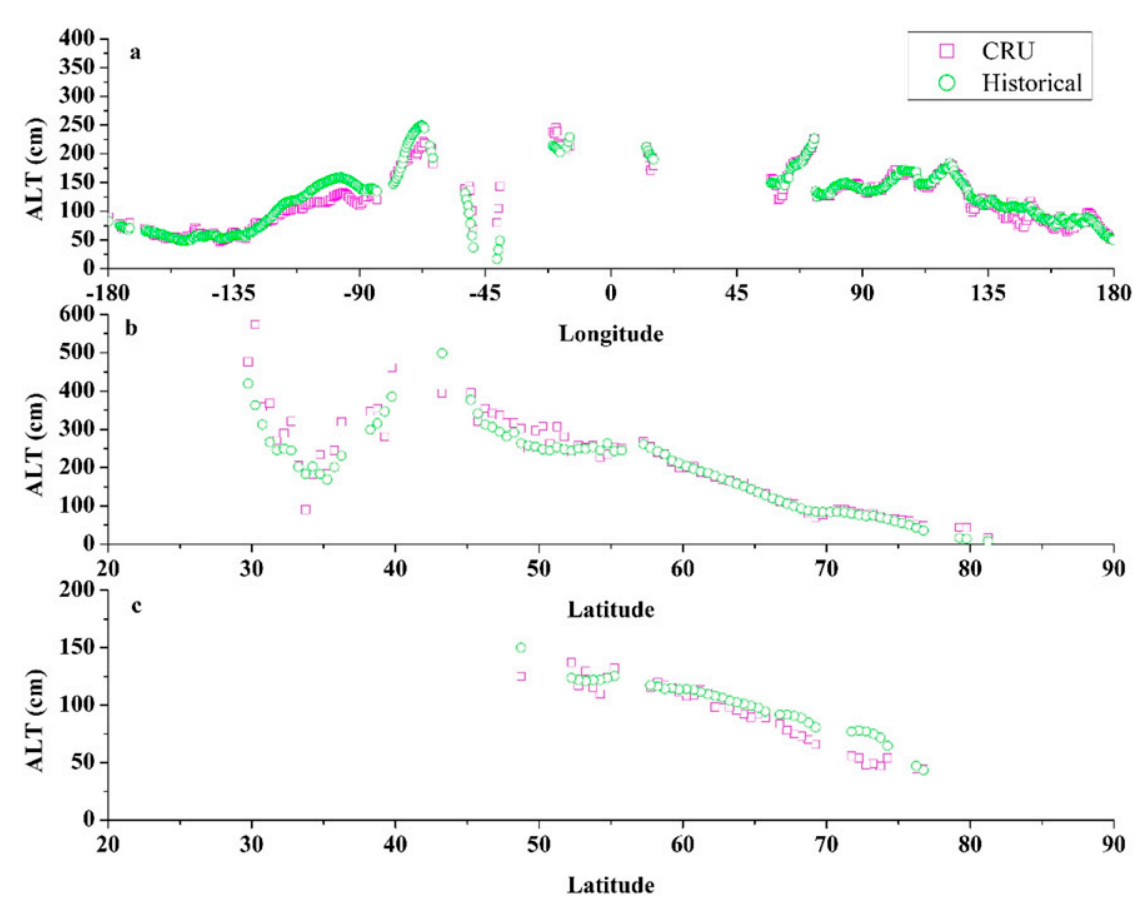

FIG. 5. ALT variability across transects at (a) $65^{\circ} \mathrm{N}$, (b) $95^{\circ} \mathrm{E}$, and (c) $120^{\circ} \mathrm{W}$. Magenta symbols represent ALT from CRU and green symbols from CMIP5 during 1971-2000.

as latitude increases. This transect represents the ALT variability across North America.

Combining the spatial patterns of the 30 -yr average ALT and the three transects of ALT in Northern Hemisphere, a greater ALT is found in both lowlatitude and high-altitude regions, while a shallower ALT is only found in high-latitude regions. Beside air temperature, ALT is also influenced by local soil parameters, land cover, and topography. In cold regions such as Arctic and subarctic environments, some land surfaces are covered by moss and peat. This surface cover can cause cooling due to a low thermal conductivity in summer, and a high thermal conductivity of the frozen, saturated overburden material in winter. In addition, underlying the surface moss cover, there is often peat and loam with a higher air volume and water content (Burn 1998; Beringer et al. 2001; Jafarov et al. 2013). Kade and Walker (2008) reported that the addition of a $10-\mathrm{cm}$ layer of moss resulted in almost a $3^{\circ} \mathrm{C}$ decrease in the mean summer soil temperature and a $15 \%$ reduction in ALT in northern Alaska. On the Qinghai-Tibetan Plateau, high elevation leads to lower temperatures compared to other areas at similar latitudes. Elevation is higher in the western plateau than in the east, resulting in mean annual air temperature in the west about $10^{\circ} \mathrm{C}$ lower than in the east (Frauenfeld et al. 2005). Compared with high-latitude regions, the vegetation cover is very sparse with dry tundra over the Qinghai-Tibetan Plateau, and it is even more sparse in the north than in the south. Because of high wind during the cold season and the sparse vegetation cover, the ground surface is usually covered by sand and gravel, especially in the north. The percentage of organic soil is in general much lower compared with some subarctic regions where land is covered by mosses and peat. $\mathrm{Wu}$ and Zhang (2010) found that soils on the QinghaiTibetan Plateau are dry and the mean ALT is greater than in high-latitude regions under the same mean annual air temperature conditions.

\section{3) Spatial ALT tRendS DURING 1901-2005}

To analyze the long-term changes of ALT derived from the thawing index, we estimated the spatial patterns of 1901-2005 ALT trends (Figs. 6a,b). ALT increased significantly in most areas, except for small regions with no changes based on the CRU dataset (Fig. 6a). The region with the highest increase in ALT was in the Alps, with a rate larger than $3 \mathrm{~cm} \mathrm{decade}^{-1}$, followed by northeastern North America between $90^{\circ}$ and $60^{\circ} \mathrm{W}$ with a rate larger than $2 \mathrm{~cm} \mathrm{decade}^{-1}$; ALT increased over the Qinghai-Tibetan Plateau at a rate of $0.5-2 \mathrm{~cm} \mathrm{decade}^{-1}$, with trends in the remaining regions of less than $2 \mathrm{~cm} \mathrm{decade}^{-1}$. ALT for 1901-2005 from CMIP5 indicates a similar trend pattern as the one from CRU (Fig. 6b). 

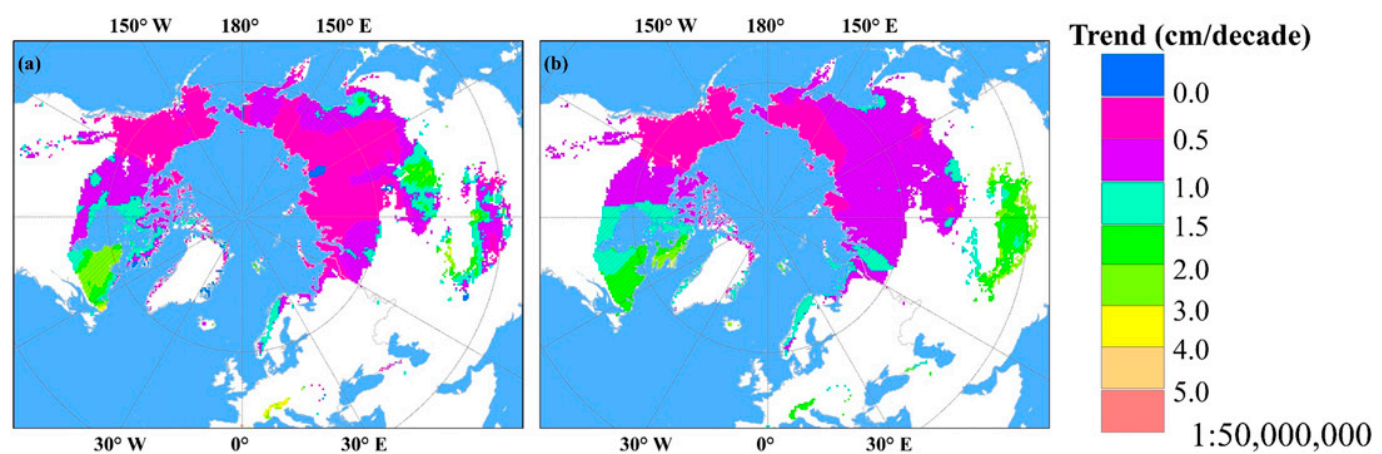

FIG. 6. Spatial variability of changes in ALT over Northern Hemisphere permafrost regions from (a) CRU during 1901-2005 and (b) ensemble mean of 16 CMIP5 models for the historical experiment during 1901-2005.

\section{b. ALT projections for the twenty-first century in the Northern Hemisphere}

\section{1) SPATIAL VARIATIONS OF ALT DERIVED FROM THAWING INDEX DURING THE TWENTY-FIRST CENTURY}

The spatial pattern of the 30-yr (2071-2100) climatology of ALT derived from the ensemble-averaged CMIP5 thawing index for the three RCPs (Figs. 7a-c) demonstrates that ALT will become greater. Areas where ALT is greater than $150 \mathrm{~cm}$ will also increase. For example, ALT changes from less than $70 \mathrm{~cm}$ in RCP2.6, $50-80 \mathrm{~cm}$ in RCP4.5, and $60-100 \mathrm{~cm}$ in RCP8.5 in Alaska. In Siberian, the extent of ALT less than $120 \mathrm{~cm}$ becomes smaller, while the extent of ALT greater than $150 \mathrm{~cm}$ increases. A similar pattern also occurs on the Qinghai-Tibetan Plateau.

A substantial difference between the three RCP experiments during 2071-2100 and the historical experiment during 1971-2000 (Figs. 7d-f) is evident. Given that the three RCP scenarios begin to diverge in the middle of the twenty-first century (Fig. 8), these 2071-2100 differences primarily reflect those RCP patterns. Positive differences were found in all permafrost regions in the Northern Hemisphere, indicating a greater ALT in the future for all RCP experiments. The largest differences are, on average, about $60 \mathrm{~cm}$ in RCP8.5, about $30 \mathrm{~cm}$ in RCP4.5, and about $18 \mathrm{~cm}$ in RCP2.6. Taking the Qinghai-Tibetan Plateau as an example, the increase is less than $40 \mathrm{~cm}$ in $\mathrm{RCP} 2.6$, $60-80 \mathrm{~cm}$ in RCP4.5, and more than $100 \mathrm{~cm}$ in RCP8.5. The spatial pattern of ALT differences between the RCP experiments and the historical experiment seems comparable. Taking RCP8.5 as an example, the maximum ALT difference is about 120 $200 \mathrm{~cm}$, mainly on the Qinghai-Tibetan Plateau, about $60-120 \mathrm{~cm}$ in northeastern North America, followed by about $20-60 \mathrm{~cm}$ in the south of the
Mongolian Plateau. The smallest increase of about 0 $20 \mathrm{~cm}$ is in Alaska.

\section{2) Projected trends In ALT}

To understand long-term ALT trends derived from CMIP5, we computed time series of area-averaged ALT during 2006-2100 from the three RCP experiments (Fig. 8) and then compared ALT trends with those from each individual CMIP5 model (Fig. 9).

Time series of the area-averaged ALT for 18502100 demonstrate substantial changes of varying magnitudes among the three RCPs experiments (Fig. 8). There is a statistically significant increase of about $0.57 \pm 0.04 \mathrm{~cm} \mathrm{decade}^{-1}$ during 1850-2005, and about $0.84 \pm 0.06 \mathrm{~cm} \mathrm{decade}^{-1}$ during 1901-2005 from the historical experiment, and about $0.79 \pm$ $0.09 \mathrm{~cm} \mathrm{decade}^{-1}$ during 1901-2014 from the CRU dataset. The RCP8.5 scenario exhibits the largest increase of $6.51 \pm 0.07 \mathrm{~cm} \mathrm{decade}^{-1}$ for 2006-2100. The RCP4.5 and RCP2.6 scenarios show a relatively smaller positive trend, at a rate of $2.56 \pm 0.07$ and $0.77 \pm 0.08 \mathrm{~cm} \mathrm{decade}^{-1}$, respectively, over the same period.

The area-averaged ALT trends show substantial differences among the 16 models (Fig. 9). The ALT trends of the 16 models show virtually the same significant increasing pattern for the historical experiment, and also for the three future scenarios. Two exceptions are the FIO-ESM's RCP4.5 simulation, which is not statistically significant, and GISS-E2-R for RCP2.6. Several models project greater rates of ALT increases than others, such as CanESM2, IPSL-CM5ALR, MIROC-ESM-CHEM, MIROC-ESM, MIROC5, and NorESM1-M. In the historical experiment, ALT derived from the GISS-E2-R model is most close to the ensemble mean, while it is IPSL-CM5A-MR for RCP2.6, MPI-ESM-MR for RCP4.5, and NorESM1-M for RCP8.5. 

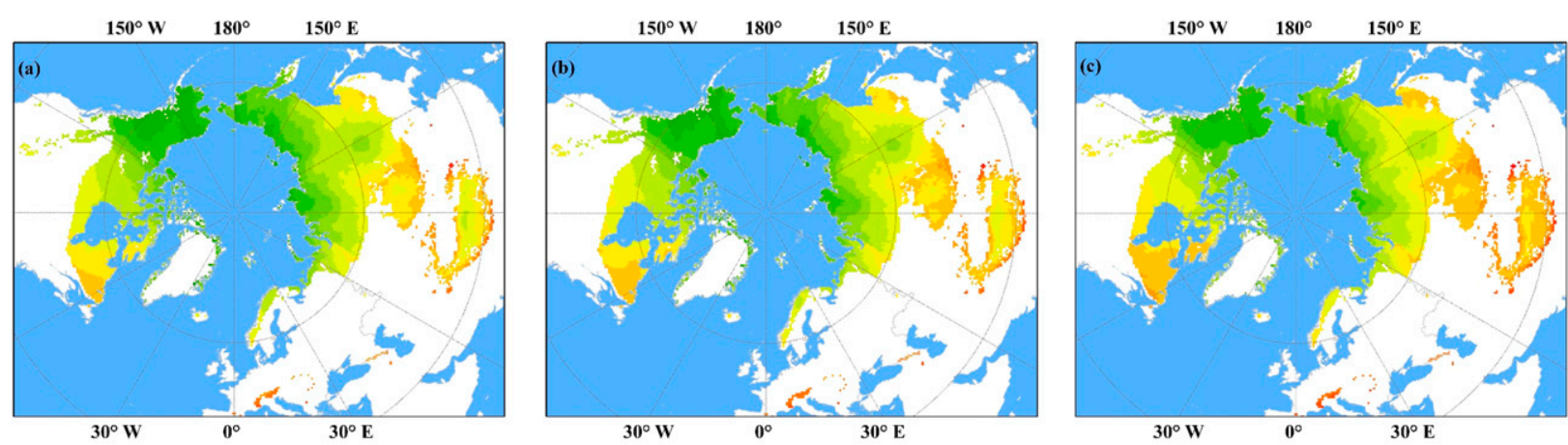

ALT(cm)

$\begin{array}{llllllllllllll}0 & 30 & 60 & 90 & 120 & 150 & 200 & 250 & 300 & 400 & 500 & 600 & 700 & 800\end{array}$
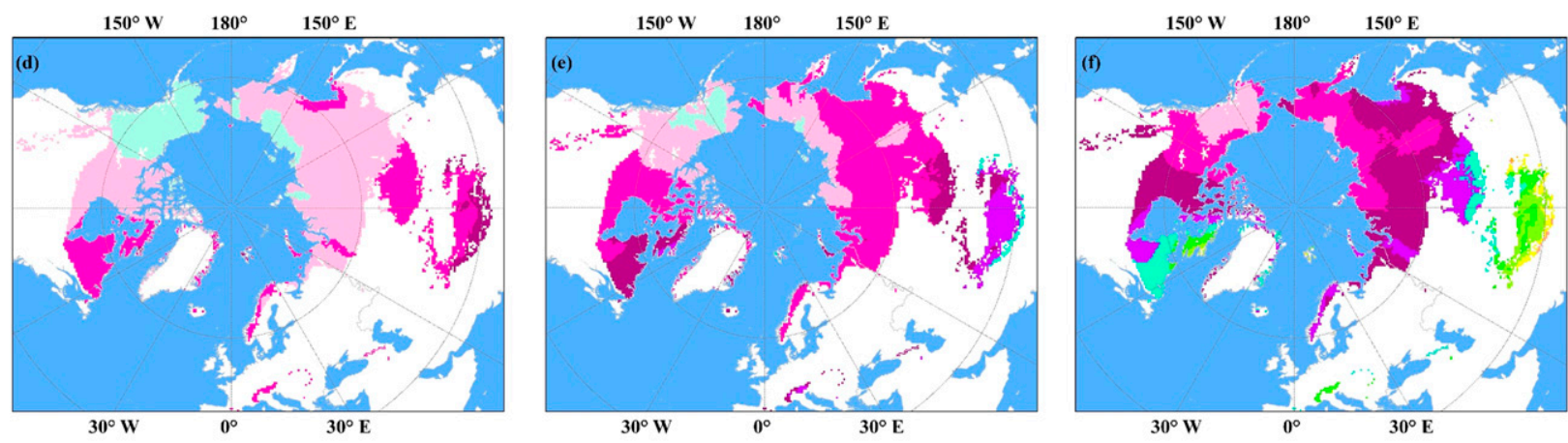

$1: 50,000,000$

ALT Difference (cm)

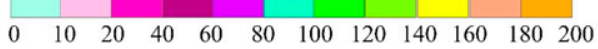

FIG. 7. Spatial climatologies of ensemble-mean 2071-2100 ALT from 16 CMIP5 models for (a) RCP2.6, (b) RCP4.5, and (c) RCP8.5 and differences between 2071-2100 climatologies of (d) RCP2.6, (e) RCP4.5, and (f) RCP8.5 and the historical 1971-2000 ALT simulation.

\section{Discussion}

Previous studies have demonstrated the feasibility of estimating ALT at different scales, from the point scale to the hemispheric scale. However, at the hemispheric scale, previous results are based on limited observational datasets. Compared to these previous studies, we used more complete observational datasets, adjusted the Stefan solution methodology to overcome the lack of data for complex variables, and provided ALT changes under contemporary and project climate changes. Although some biases in the $E$ factor using the simplified Stefan solution produce uncertainties in the ALT estimate, the standard deviation of the $E$ factor (Figs. 1 and 2) and the ALT verification between observed and simulated data (Fig. 10) suggest that the simplified Stefan solution can be effectively used for ALT calculations at the hemisphere scale (Anisimov et al. 1997).

\section{a. Uncertainties of ALT from different methods}

We used in situ ALT data as ground truth based on 347 monitoring sites over the Northern Hemisphere permafrost regions (Fig. 3). These in situ measurements were compiled in different regions, by different people, using different instruments and methods. Thus, these data naturally contain a variety of differences, errors, and uncertainties. As described in Brown et al. (2000), ALT measurements obtained from probing do not necessarily correspond to the maximum thaw penetration as indicated by the $0^{\circ} \mathrm{C}$ isotherm from thaw tubes or soil temperature measurements. Furthermore, replicate mechanical probing of ALT is performed annually at grid points using metal rods, inserted into the soil to the point of resistance. The probing time varies ranging from mid-August to mid-September in the Arctic and subarctic regions (Brown et al. 2000). While the maximum thaw depth generally occurs during this period, this is not necessarily the case at all sites, such as in midlatitudinal mountainous areas with warm permafrost (Luo et al. 2016). The IPA initiated the CALM program, intending to standardize techniques and methods to measure ALT (Brown et al. 2000). ALT data from CALM and GTN-P sites are comparable. 


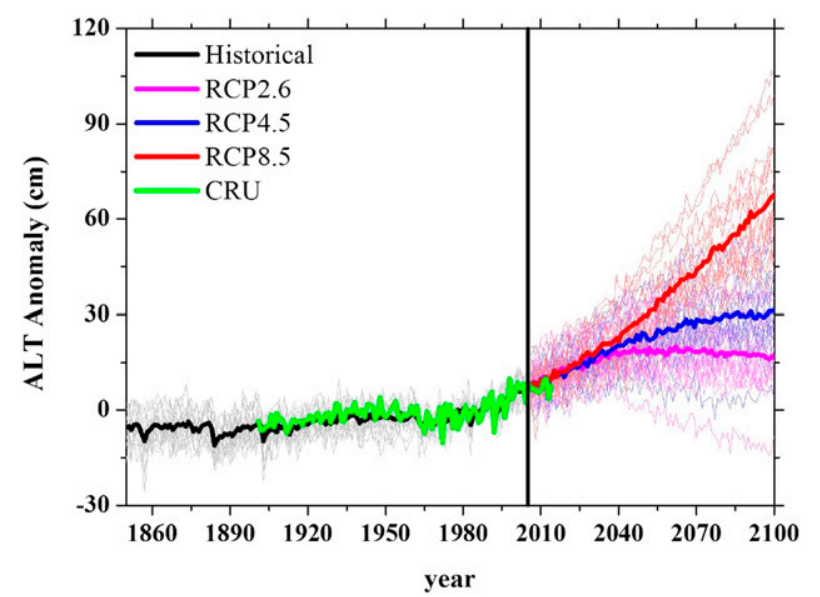

FIG. 8. Time series of ALT derived from CRU and CMIP5 for permafrost regions across the Northern Hemisphere. Shown are the ALT anomaly from the CRU dataset during 1901-2014 (thick green line), the ensemble-mean ALT anomaly from CMIP5 historical experiment during 1850-2005 (thick black line), and the projected ALT anomaly from 16 CMIP5 models during 2005-2100: RCP2.6 (thick magenta line), RCP4.5 (thick blue line), and RCP8.5 (thick red line).

Regarding ALT computed from daily and monthly soil temperatures, Frauenfeld et al. (2004) estimated the errors and uncertainties based on data from 14 stations across Siberia. The results demonstrate that there is a strong statistically significant relationship, but ALT from monthly mean soil temperatures is underestimated by approximately $6 \mathrm{~cm}$. An important caveat is that in situ measurements do not consider the surface deformation due to frost heave and thaw settlement. The magnitude of frost heave and thaw settlement can be up to several centimeters. The long-term accumulated thaw settlement could be much greater in some areas because of the melting of ice-rich or ice-saturated permafrost near the permafrost table. This may be one of the reasons why, despite climate warming in northern Alaska, ALT shows little or no significant change based on CALM measurements. Satellite remote sensing techniques, such as Interferometric Synthetic Aperture Radar (InSAR), have been used to detect the surface deformation and ALT in Arctic and sub-Arctic regions (Liu et al. 2012, 2014). In this study, our application of the Stefan equation assumes a stable surface, and consequently the ALT results do not include any settlement of the surface. Therefore, future modeling efforts should attempt to include surface deformation for ALT estimation. Other caveats are that we used the IPA permafrost extent data from 1998 (Brown et al. 1998; Zhang et al. 1999) and thereby assume there has been no change in areal extent over the study period (18502100). This assumption may lead to underestimates of ALT for the historical experiment, and ALT overestimates for the three RCP experiments.

Using ALT from in situ measurements as the ground truth, we validated simulated ALT from CRU data (Fig. 10). The results demonstrate that there is generally a good agreement between observed and simulated ALTs with $R=0.84$, MPE of $4.7 \%$, MBE of $-11.7 \mathrm{~cm}$, and RMSE of $64 \mathrm{~cm}$. As for the differences or potential errors and uncertainties, there are several possible reasons. Scale issues due to the spatial latitude-longitude resolution of estimated ALT being $0.5^{\circ} \times 0.5^{\circ}$, while observations are either at a point scale (temperature profiles) or a grid of $10 \mathrm{~m} \times 10 \mathrm{~m}, 100 \mathrm{~m} \times 100 \mathrm{~m}$, or $1000 \mathrm{~m} \times 1000 \mathrm{~m}$ at CALM sites. The largest CALM grid is $1.0 \mathrm{~km}^{2}$. From the point scale to different grid sizes, soil properties, soil moisture, morphology, land cover, and vegetation likely change substantially. Within a $0.5^{\circ} \times 0.5^{\circ}$ grid, these differences could be even greater. Additionally, complex terrain issues prevent

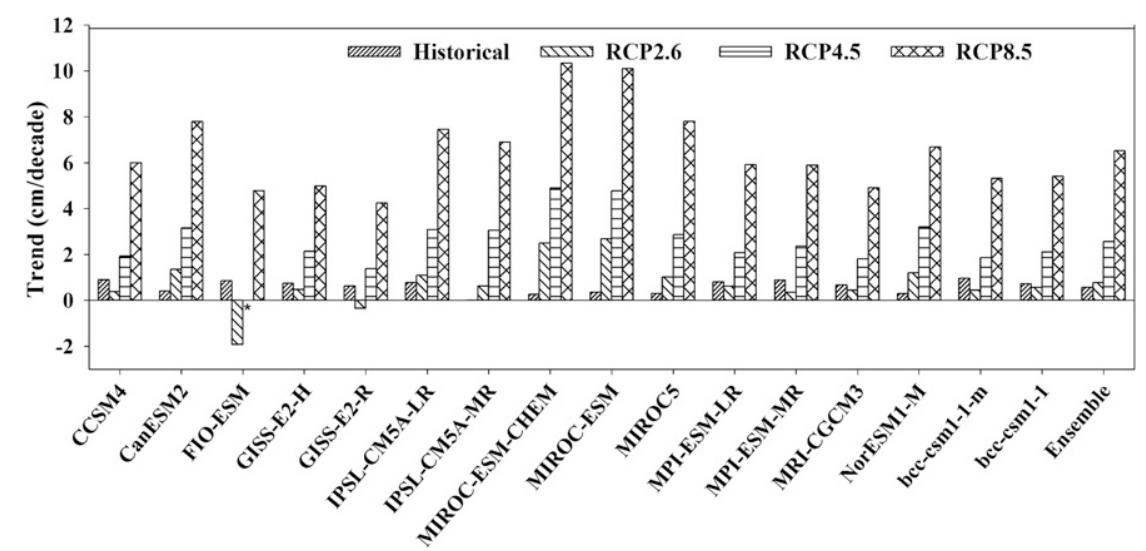

FIG. 9. Trends in area-averaged ALT across Northern Hemisphere permafrost regions from different CMIP5 experiments during 1850-2100: historical, RCP2.6, RCP4.5, and RCP8.5. 


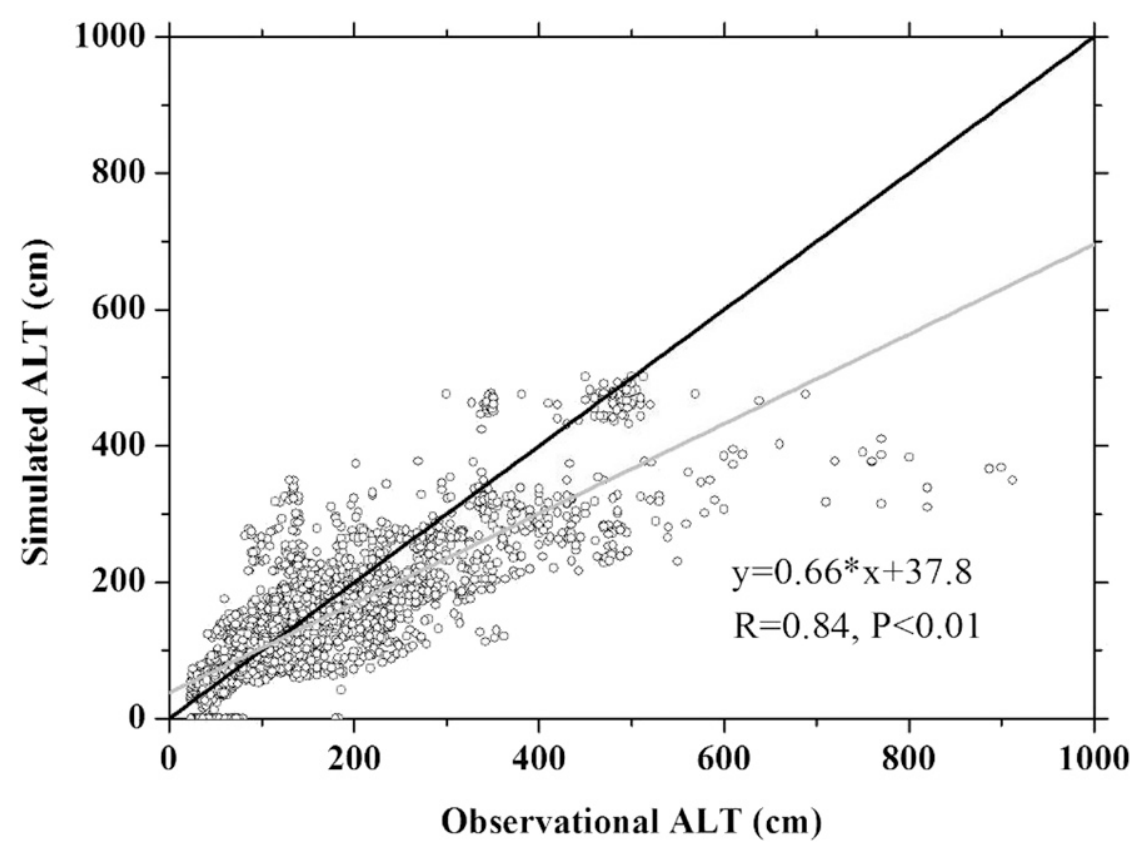

FIG. 10. Scatterplot of in situ and simulated ALT derived from CRU thawing index across the Northern Hemisphere. The gray solid line is the linear fit, 1:1 line is in black.

field measurements from accurately representing an area's mean value (Park et al. 2013). Potential sources of errors or uncertainties can be introduced when the thawing index is estimated from monthly mean CRU air temperature, because the gridding process can introduce errors. Furthermore, using monthly rather than daily mean air temperature to calculate thawing index can introduce uncertainties up to 5\% (Zhang et al. 1997; Frauenfeld et al. 2007). Additional uncertainties may arise when the $E$ factor is estimated with the accumulated thawing index and thaw depth because it changes spatially and temporally due to different soil properties and variable soil moisture content. Finally, in situ ALT measurements have their own inherent errors and uncertainties.

\section{b. ALT driving variables}

There are many factors controlling changes in ALT, including climatic and nonclimatic factors, many of which are incorporated into the $E$ factor. Air temperature is perhaps a direct and main driver, and likely contributes the most to changes in ALT (Zhang and Stamnes 1998; Åkerman and Johansson 2008).

Precipitation is another important factor influencing ALT because it increases soil moisture, which increases the soil's thermal conductivity, potentially leading to a greater ALT (Park et al. 2013; Slater and Lawrence 2013; Subin et al. 2013; Park et al. 2015). Anisimov et al. (1997) demonstrated that the effect of soil moisture changes on ALT is substantial for silt soils, less pronounced for sandy soils, and small for soils with high organic content. More summer precipitation implies a wetter ground surface and more energy expended via evaporation, thereby cooling the ground surface (Zhang et al. 2001) and decreasing ALT. However, under global warming conditions, extreme rainfall events may increase, which would lead to increased runoff. Therefore, not all precipitation would contribute to increased latent heating through evaporation (Traxl et al. 2016). Further, not all regions are expected to see wetter conditions with a changing climate (Zhao and Dai 2015). Additional research should focus on the effects of precipitation on ALT and the analogous physical mechanisms.

Studies have shown that snow cover may play a significant role on ALT changes. High albedo and emissivity result in cooling the snow surface and the underlying soils. The low thermal conductivity of snow can be an efficient insulator, preventing the ground surface from cooling and keeping soil temperatures elevated (Zhang 2005). During snowmelt, latent heat is needed, which may lead to a thermal offset between the air and soil. The insulating effect of snow cover may be more sensitive in colder northern regions where soil temperature is largely based on the thermal regimes controlled by the long winter snow season (Zhang et al. 1996; Ling and Zhang 2003; Zhang 2005; Osterkamp 2007; Lawrence and Slater 2010; Park et al. 2015). 
In addition to these climate factors, ALT changes also depend on many nonclimatic variables such as geomorphology, vegetation, land cover, soil properties, soil moisture, microrelief, slope, and aspect (Woo et al. 2007; Yi et al. 2007, 2013; Gao et al. 2016). ALT changes substantially over short distances because the soil temperature, moisture, and heat transfer are mainly determined by subsurface soil properties, which are a product of the interactions among many highly localized environmental factors (Nelson et al. 1997; Haeberli 2013; Gangodagamage et al. 2014; Gao et al. 2016). Although previous studies have focused on the environmental factors influencing ALT, most still focus on primarily qualitative knowledge. Thus, these factors should be the focus of future research, and the physical mechanisms influencing ALT should be examined.

\section{Conclusions}

This study investigated the spatiotemporal variability of ALT under contemporary and projected climate change in the Northern Hemisphere based on CRU data and CMIP5 outputs. The spatial patterns of the ALT climatology derived from CRU and CMIP5 are similar, with maximum ALTs located in the Alps, the QinghaiTibetan Plateau, and the Mongolian Plateau. Relatively shallower ALT is found in high-latitude regions, especially in Alaska and eastern Siberia. A transect across $65^{\circ} \mathrm{N}$ indicates that ALT becomes greater from west to east in North America, but deepens from east to west on the Eurasian continent. A south-north Eurasian $\left(95^{\circ} \mathrm{E}\right)$ transect representing ALT variability from the QinghaiTibetan Plateau across the Mongolian Plateau and into Siberia demonstrates that ALT decreases with increasing latitude. A North American $\left(120^{\circ} \mathrm{W}\right)$ transect shows similar ALT variability across North America.

ALT differences between the historical period and the three future RCP experiments indicate similar spatial patterns, with positive trends and largest increases on the Qinghai-Tibetan Plateau, and smallest increases in Alaska. The largest ALT increases are observed for the RCP8.5 experiment, followed by RCP4.5, while RCP2.6 projects the smallest changes.

Based on the time series of area-averaged ALT derived from CRU and CMIP5, a statistically significant increase is found over the study period. The areaaveraged ALT has a statistically significant increase of $0.79 \pm 0.09 \mathrm{~cm} \mathrm{decade}^{-1}$ during 1901-2014 based on CRU data, and $0.57 \pm 0.04 \mathrm{~cm} \mathrm{decade}^{-1}$ during 1850 2005 in the historical experiment. For the three RCPs, the area-averaged ALT increases at a rate of $0.77 \pm$ $0.08 \mathrm{~cm} \mathrm{decade}^{-1}$ in RCP2.6, $2.56 \pm 0.07 \mathrm{~cm} \mathrm{decade}^{-1}$ in
$\mathrm{RCP} 4.5$, and $6.51 \pm 0.07 \mathrm{~cm} \mathrm{decade}^{-1}$ in RCP8.5 during 2006-2100 in the Northern Hemisphere.

Acknowledgments. This study was funded by the National Natural Science Foundation of China (Grant 91325202), the National Key Scientific Research Program of China (Grant 2013CBA01802), and the Fundamental Research Funds for the Central Universities (lzujbky-2015-217, lzujbky-2015-215, and lzujbky-2015ot03). We acknowledged the international modeling groups for providing their model outputs and the Program for Climate Model Diagnosis and Intercomparison (PCMDI) for collecting and archiving the model datasets. We thank Circumpolar Active Layer Monitoring and Global Terrestrial Network for Permafrost for the ALT datasets. We also thank the editor and reviewers for their constructive and thoughtful comments, which helped us to improve this manuscript.

\section{REFERENCES}

Åkerman, H. J., and M. Johansson, 2008: Thawing permafrost and thicker active layers in sub-Arctic Sweden. Permafrost Periglac. Processes, 19, 279-292, https://doi.org/10.1002/ ppp.626.

Anisimov, O. A., N. I. Shiklomanov, and F. E. Nelson, 1997: Global warming and active-layer thickness: Results from transient general circulation models. Global Planet. Change, 15, 61-77, https://doi.org/10.1016/S0921-8181(97)00009-X.

$\longrightarrow,-$, and $\longrightarrow, 2002$ : Variability of seasonal thaw depth in permafrost regions: A stochastic modeling approach. Ecol. Modell., 153, 217-227, https://doi.org/10.1016/S0304-3800(02)00016-9.

, V. A. Lobanov, S. A. Reneva, N. I. Shiklomanov, T. Zhang, and F. E. Nelson, 2007: Uncertainties in gridded air temperature fields and effects on predictive active layer modeling. J. Geophys. Res., 112, F02S14, https://doi.org/10.1029/ 2006JF000593.

Arzhanov, M. M., A. V. Eliseev, and I. I. Mokhov, 2013: Impact of climate changes over the extratropical land on permafrost dynamics under RCP scenarios in the 21st century as simulated by the IAP RAS climate model. Russ. Meteor. Hydrol., 38, 456-464, https://doi.org/10.3103/S1068373913070030.

Beringer, J., A. H. Lynch, F. S. Chapin III, M. Mack, and G. B. Bonan, 2001: The representation of Arctic soils in the land surface model: The importance of mosses. J. Climate, 14, 33243335, https://doi.org/10.1175/1520-0442(2001)014<3324: TROASI $>2.0 . \mathrm{CO} ; 2$.

Betts, R. A., C. D. Jones, J. R. Knight, R. F. Keeling, and J. J. Kennedy, 2016: El Niño and a record $\mathrm{CO}_{2}$ rise. Nat. Climate Change, 6, 806-810, https://doi.org/10.1038/nclimate3063.

Biskaborn, B. K., and Coauthors, 2015: Quality assessment of permafrost thermal state and active layer thickness data in GTNP. GEOQuébec 2015, Québec City, QC, Canada, Canadian Geotechnical Society, http://epic.awi.de/39068/.

Blunden, J., and D. S. Arndt, Eds., 2016: State of the Climate in 2015. Bull. Amer. Meteor. Soc., 97 (8), SI-S275, https://doi.org/ 10.1175/2016BAMSStateoftheClimate.1.

Brown, J., O. J. Ferrians Jr., J. A. Heginbottom, and E. S. Melnikov, 1998: Circum-Arctic map of permafrost and ground 
ice conditions (revised February 2001). National Snow and Ice Data Center, https://nsidc.org/data/ggd318.

K. M. Hinkel, and F. E. Nelson, 2000: The Circumpolar Active Layer Monitoring (CALM) program: Research designs and initial results. Polar Geogr., 24, 166-258, https://doi.org/ 10.1080/10889370009377698.

Burn, C. R., 1998: The response (1958-1997) of permafrost and near-surface ground temperatures to forest fire, Takhini River valley, southern Yukon Territory. Can. J. Earth Sci., 35, 184199, https://doi.org/10.1139/e97-105.

Chapin, F. S., III, and Coauthors, 2005: Role of land-surface changes in Arctic summer warming. Science, 310, 657-660, https://doi.org/10.1126/science.1117368.

Chen, L., and O. W. Frauenfeld, 2014: Surface air temperature changes over the twentieth and twenty-first centuries in China simulated by 20 CMIP5 models. J. Climate, 27, 3920-3937, https://doi.org/10.1175/JCLI-D-13-00465.1.

Dong, M., C.-Q. Wang, B. Li, D.-Y. Tang, J. Yang, and W.-P. Song, 2010: Study on soil available zinc with GA-RBF-neuralnetwork-based spatial interpolation method. Acta Pedol. Sin., 47, 42-50.

Fagan, J. D., and F. E. Nelson, 2017: Spatial sampling design in the Circumpolar Active Layer Monitoring programme. Permafrost Periglac. Processes., 28, 42-51, https://doi.org/10.1002/ ppp.1904.

Ford, T. W., and O. W. Frauenfeld, 2016: Surface-atmosphere moisture interactions in the frozen ground regions of Eurasia. Sci. Rep., 6, 19163, https://doi.org/10.1038/srep19163.

Frauenfeld, O. W., T. Zhang, R. G. Barry, and D. Gilichinsky, 2004: Interdecadal changes in seasonal freeze and thaw depths in Russia. J. Geophys. Res., 109, D05101, https://doi.org/10.1029/ 2003JD004245.

, — , and M. C. Serreze, 2005: Climate change and variability using European Centre for Medium-Range Weather Forecasts reanalysis (ERA-40) temperatures on the Tibetan Plateau. J. Geophys. Res., 110, D02101, https://doi.org/10.1029/ 2004JD005230.

- - , and J. L. Mccreight, 2007: Northern Hemisphere freezing/thawing index variations over the twentieth century. Int. J. Climatol., 27, 47-63, https://doi.org/10.1002/joc.1372.

Gangodagamage, C., and Coauthors, 2014: Extrapolating active layer thickness measurements across Arctic polygonal terrain using LiDAR and NDVI data sets. Water Resour. Res., 50, 6339-6357, https://doi.org/10.1002/2013WR014283.

Gao, T., T. Zhang, X. Wan, S. Kang, M. Sillanpää, Y. Zheng, and L. Cao, 2016: Influence of microtopography on active layer thaw depths in Qilian Mountain, northeastern Tibetan Plateau. Environ. Earth Sci., 75, 382, https://doi.org/10.1007/ s12665-015-5196-7.

Gilichinsky, D. A., R. G. Barry, S. S. Bykhovets, V. A. Sorokovikov, T. Zhang, S. L. Zudin, and D. G. FedorovDavydov, 1998: A century of temperature observations of soil climate: Methods of analysis and long-term trends. Proc. Seventh Int. Conf. on Permafrost, Yellowknife, NT, Canada, International Permafrost Association, 313-317.

Goodrich, L. E., 1978: Efficient numerical technique for onedimensional thermal problems with phase change. Int. J. Heat Mass Transfer, 21, 615-621, https://doi.org/10.1016/ 0017-9310(78)90058-3.

Gotway, C. A., R. B. Ferguson, G. W. Hergert, and T. A. Peterson, 1996: Comparison of kriging and inverse-distance methods for mapping soil parameters. Soil Sci. Soc. Amer. J., 60, 1237-1247, https://doi.org/10.2136/sssaj1996.03615995006000040040x.
Guo, D., and H. Wang, 2016: CMIP5 permafrost degradation projection: A comparison among different regions. $J$. Geophys. Res. Atmos., 121, 4499-4517, https://doi.org/10.1002/ 2015JD024108.

Haeberli, W., 2013: Mountain permafrost-Research frontiers and a special long-term challenge. Cold Reg. Sci. Technol., 96, 71-76, https://doi.org/10.1016/j.coldregions.2013.02.004.

Hinkel, K. M., W. R. Eisner, J. G. Bockheim, F. E. Nelson, K. M. Peterson, and X. Dai, 2003: Spatial extent, age, and carbon stocks in drained thaw lake basins on the Barrow Peninsula, Alaska. Arct. Antarct. Alp. Res., 35, 291-300, https://doi.org/ 10.1657/1523-0430(2003)035[0291:SEAACS]2.0.CO;2.

Hinzman, L. D., and Coauthors, 2005: Evidence and implications of recent climate change in northern Alaska and other Arctic regions. Climatic Change, 72, 251-298, https://doi.org/10.1007/ s10584-005-5352-2.

IPCC, 2013: Climate Change 2013: The Physical Science Basis. Cambridge University Press, 1535 pp., https://doi.org/10.1017/ CBO9781107415324.

Jafarov, E. E., V. E. Romanovsky, H. Genet, A. D. McGuire, and S. S. Marchenko, 2013: The effects of fire on the thermal stability of permafrost in lowland and upland black spruce forests of interior Alaska in a changing climate. Environ. Res. Lett., $\mathbf{8}$, 035030, https://doi.org/10.1088/1748-9326/8/3/035030.

Jeong, J.-H., and Coauthors, 2012: Greening in the circumpolar high-latitude may amplify warming in the growing season. Climate Dyn., 38, 1421-1431, https://doi.org/10.1007/s00382-011-1142-x.

Joetzjer, E., H. Douville, C. Delire, and P. Ciais, 2013: Present-day and future Amazonian precipitation in global climate models: CMIP5 versus CMIP3. Climate Dyn., 41, 2921-2936, https:// doi.org/10.1007/s00382-012-1644-1.

Kade, A., and D. A. Walker, 2008: Experimental alteration of vegetation on nonsorted circles: Effects on cryogenic activity and implications for climate change in the Arctic. Arct. Antarct. Alp. Res., 40, 96-103, https://doi.org/10.1657/ 1523-0430(06-029)[KADE]2.0.CO;2.

Kaverin, D., G. Mazhitova, A. Pastukhov, and F. Rivkin, 2012: The transition layer in permafrost-affected soils, northeast European Russia. Proc. 10th Int. Conf. on Permafrost, Salekhard, Russia, International Permafrost Association, 145-148.

Knutson, T. R., and Coauthors, 2013: Dynamical downscaling projections of twenty-first-century Atlantic hurricane activity: CMIP3 and CMIP5 model-based scenarios. J. Climate, 26, 6591-6617, https://doi.org/10.1175/JCLI-D-12-00539.1.

Koven, C. D., W. J. Riley, and A. Stern, 2013: Analysis of permafrost thermal dynamics and response to climate change in the CMIP5 Earth system models. J. Climate, 26, 1877-1900, https://doi.org/10.1175/JCLI-D-12-00228.1.

Lawrence, D. M., and A. G. Slater, 2005: A projection of severe near-surface permafrost degradation during the 21st century. Geophys. Res. Lett., 32, L24401, https://doi.org/10.1029/ 2005 GL025080.

— and - 2010: The contribution of snow condition trends to future ground climate. Climate Dyn., 34, 969-981, https:// doi.org/10.1007/s00382-009-0537-4.

Ling, F., and T. Zhang, 2003: Impact of the timing and duration of seasonal snow cover on the active layer and permafrost in the Alaskan Arctic. Permafrost Periglac. Processes, 14, 141-150, https://doi.org/10.1002/ppp.445.

Liu, L., K. Schaefer, T. Zhang, and J. Wahr, 2012: Estimating 19922000 average active layer thickness on the Alaskan North Slope from remotely sensed surface subsidence. J. Geophys. Res., 117, F01005, https://doi.org/10.1029/2011JF002041. 
—, E. E. Jafarov, K. M. Schaefer, B. M. Jones, H. A. Zebker, C. A. Williams, J. Rogan, and T. Zhang, 2014: InSAR detects increase in surface subsidence caused by an Arctic tundra fire. Geophys. Res. Lett., 41, 3906-3913, https://doi.org/10.1002/ 2014 GL060533.

Luo, D., Q. Wu, H. Jin, S. S. Marchenko, L. Lü, and S. Gao, 2016: Recent changes in the active layer thickness across the Northern Hemisphere. Environ. Earth Sci., 75, 555, https:// doi.org/10.1007/s12665-015-5229-2.

Mishra, U., and W. J. Riley, 2014: Active-layer thickness across Alaska: Comparing observation-based estimates with CMIP5 Earth system model predictions. Soil Sci. Soc. Amer. J., 78, 894-902, https://doi.org/10.2136/sssaj2013.11.0484.

Mu, C., T. Zhang, Q. Wu, X. Peng, B. Cao, X. Zhang, and G. Cheng, 2015: Editorial: Organic carbon pools in permafrost regions on the Qinghai-Xizang (Tibetan) Plateau. Cryosphere, 9, 479-486, https://doi.org/10.5194/tc-9-479-2015.

,$- \ldots$, X. Zhang, B. Cao, and X. Peng, 2016: Sensitivity of soil organic matter decomposition to temperature at different depths in permafrost regions on the northern Qinghai-Tibet Plateau. Eur. J. Soil Sci., 67, 773-781, https://doi.org/10.1111/ ejss.12386.

Nelson, F. E., and S. I. Outcalt, 1987: A computational method for prediction and regionalization of permafrost. Arct. Alp. Res., 19, 279-288, https://doi.org/10.2307/1551363.

—, N. I. Shiklomanov, G. R. Mueller, K. M. Hinkel, D. A. Walker, and J. G. Bockheim, 1997: Estimating active-layer thickness over a large region: Kuparuk River basin, Alaska, U.S.A. Arct. Alp. Res., 29, 367-378, https://doi.org/10.2307/ 1551985.

Oelke, C., and T. Zhang, 2007: Modeling the active-layer depth over the Tibetan Plateau. Arct. Antarct. Alp. Res., 39, 714-722, https://doi.org/10.1657/1523-0430(06-200)[OELKE]2.0.CO;2.

,-- M. C. Serreze, and R. L. Armstrong, 2003: Regionalscale modeling of soil freeze/thaw over the Arctic drainage basin. J. Geophys. Res., 108, 4341, https://doi.org/10.1029/ 2002JD002722.

,$- \ldots$, and — 2004: Modeling evidence for recent warming of the Arctic soil thermal regime. Geophys. Res. Lett., 31, L07208, https://doi.org/10.1029/2003GL019300.

Osterkamp, T. E., 2007: Characteristics of the recent warming of permafrost in Alaska. J. Geophys. Res., 112, F02S02, https:// doi.org/10.1029/2006JF000578.

Pang, Q., L. Zhao, S. Li, and Y. Ding, 2012: Active layer thickness variations on the Qinghai-Tibet Plateau under the scenarios of climate change. Environ. Earth Sci., 66, 849-857, https:// doi.org/10.1007/s12665-011-1296-1.

Park, H., J. Walsh, A. N. Fedorov, A. B. Sherstiukov, Y. Iijima, and T. Ohata, 2013: The influence of climate and hydrological variables on opposite anomaly in active-layer thickness between Eurasian and North American watersheds. Cryosphere, 7, 631-645, https://doi.org/10.5194/tc-7-631-2013.

—, A. N. Fedorov, M. N. Zheleznyak, P. Y. Konstantinov, and J. E. Walsh, 2015: Effect of snow cover on pan-Arctic permafrost thermal regimes. Climate Dyn., 44, 2873-2895, https:// doi.org/10.1007/s00382-014-2356-5.

—, Y. Kim, and J. S. Kimball, 2016: Widespread permafrost vulnerability and soil active layer increases over the high northern latitudes inferred from satellite remote sensing and process model assessments. Remote Sens. Environ., 175, 349358, https://doi.org/10.1016/j.rse.2015.12.046.

Peng, X., T. Zhang, B. Cao, Q. Wang, K. Wang, W. Shao, and H. Guo, 2016: Changes in freezing-thawing index and soil freeze depth over the Heihe River basin, western China. Arct. Antarct. Alp. Res., 48, 161-176, https://doi.org/10.1657/ AAAR00C-13-127.

Pepin, N., and Coauthors, 2015: Elevation-dependent warming in mountain regions of the world. Nat. Climate Change, 5, 424430, https://doi.org/10.1038/nclimate2563.

Robinson, T. P., and G. Metternicht, 2006: Testing the performance of spatial interpolation techniques for mapping soil properties. Comput. Electron. Agric., 50, 97-108, https:// doi.org/10.1016/j.compag.2005.07.003.

Romanovsky, V. E., and T. E. Osterkamp, 1995: Interannual variations of the thermal regime of the active layer and near-surface permafrost in northern Alaska. Permafrost Periglac. Processes, 6, 313-335, https://doi.org/10.1002/ ppp.3430060404.

Rothrock, D. A., Y. Yu, and G. A. Maykut, 1999: Thinning of the Arctic sea-ice cover. Geophys. Res. Lett., 26, 3469-3472, https://doi.org/10.1029/1999GL010863.

Schädel, C., and Coauthors, 2016: Potential carbon emissions dominated by carbon dioxide from thawed permafrost soils. Nat. Climate Change, 6, 950-953, https://doi.org/10.1038/ nclimate 3054 .

Screen, J. A., and I. Simmonds, 2010: The central role of diminishing sea ice in recent Arctic temperature amplification. Nature, 464, 1334-1337, https://doi.org/10.1038/nature09051.

Serreze, M., and Coauthors, 2000: Observational evidence of recent change in the northern high-latitude environment. Climatic Change, 46, 159-207, https://doi.org/10.1023/A: 1005504031923

Shiklomanov, N. I., and F. E. Nelson, 2002: Active-layer mapping at regional scales: A 13-year spatial time series for the Kuparuk region, north-central Alaska. Permafrost Periglac. Processes, 13, 219-230, https://doi.org/10.1002/ppp.425.

- D. A. Streletskiy, and F. E. Nelson, 2012: Northern Hemisphere component of the global Circumpolar Active Layer Monitoring (CALM) program. Proc. 10th Int. Conf. on Permafrost, Salekhard, Russia, International Permafrost Association, 377-382.

Shroder, J. F., W. Haeberli, and C. Whiteman, Eds., 2014: Snow and Ice-Related Hazards, Risks, and Disasters. Academic Press, 812 pp.

Slater, A. G., and D. M. Lawrence, 2013: Diagnosing present and future permafrost from climate models. J. Climate, 26, 56085623, https://doi.org/10.1175/JCLI-D-12-00341.1.

Smith, S. L., S. A. Wolfe, D. W. Riseborough, and F. M. Nixon, 2009: Active-layer characteristics and summer climatic indices, Mackenzie Valley, Northwest Territories, Canada. Permafrost Periglac. Processes, 20, 201-220, https://doi.org/ 10.1002/ppp.651.

, V. E. Romanovsky, A. G. Lewkowicz, C. R. Burn, M. Allard, G. D. Clow, K. Yoshikawa, and J. Throop, 2010: Thermal state of permafrost in North America: A contribution to the international polar year. Permafrost Periglac. Processes, 21, 117135, https://doi.org/10.1002/ppp.690.

Streletskiy, D. A., N. I. Shiklomanov, F. E. Nelson, and A. E. Klene, 2008: 13 years of observations at Alaskan CALM sites: Long-term active layer and ground surface temperature trends. Proc. Ninth Int. Conf. on Permafrost, Fairbanks, AK, International Permafrost Association, 1727-1732.

,-- , and - , 2012: Spatial variability of permafrost activelayer thickness under contemporary and projected climate in northern Alaska. Polar Geogr., 35, 95-116, https://doi.org/ 10.1080/1088937X.2012.680204. 
- A. B. Sherstiukov, O. W. Frauenfeld, and F. E. Nelson, 2015: Changes in the 1963-2013 shallow ground thermal regime in Russian permafrost regions. Environ. Res. Lett., 10, 125005, https://doi.org/10.1088/1748-9326/10/12/125005.

Subin, Z. M., C. D. Koven, W. J. Riley, M. S. Torn, D. M. Lawrence, and S. C. Swenson, 2013: Effects of soil moisture on the responses of soil temperatures to climate change in cold regions. J. Climate, 26, 3139-3158, https://doi.org/10.1175/ JCLI-D-12-00305.1.

Symon, C., L. Arris, and B. Heal, Eds., 2004: Impacts of a Warming Arctic: Arctic Climate Impact Assessment. Cambridge University Press, 139 pp.

Taylor, K. E., R. J. Stouffer, and G. A. Meehl, 2012: An overview of CMIP5 and the experiment design. Bull. Amer. Meteor. Soc., 93, 485-498, https://doi.org/10.1175/BAMS-D-11-00094.1.

Traxl, D., N. Boers, A. Rheinwalt, B. Goswami, and J. Kurths, 2016: The size distribution of spatiotemporal extreme rainfall clusters around the globe. Geophys. Res. Lett., 43, 9939-9947, https://doi.org/10.1002/2016GL070692.

Vaughan, D. G., and Coauthors, 2013: Observations: Cryosphere. Climate Change 2013: The Physical Science Basis, T. F. Stocker et al., Eds., Cambridge University Press, 317-382.

Velicogna, I., J. Tong, and T. Zhang, and J. S. Kimball, 2012: Increasing subsurface water storage in discontinuous permafrost areas of the Lena River basin, Eurasia, detected from GRACE. Geophys. Res. Lett., 39, L09403, https://doi.org/ 10.1029/2012GL051623.

Wang, G., S. Sun, and R. Mei, 2011: Vegetation dynamics contributes to the multi-decadal variability of precipitation in the Amazon region. Geophys. Res. Lett., 38, L19703, https:// doi.org/10.1029/2011GL049017.

Wang, Q., T. Zhang, X. Peng, B. Cao, and Q. Wu, 2015: Changes of soil thermal regimes in the Heihe River basin over western China. Arct. Antarct. Alp. Res., 47, 231-241, https://doi.org/ 10.1657/AAAR00C-14-012.

Woo, M.-K., M. Mollinga, and S. L. Smith, 2007: Climate warming and active layer thaw in the boreal and tundra environments of the Mackenzie Valley. Can. J. Earth Sci., 44, 733-743, https:// doi.org/10.1139/e06-121.

Wu, Q., and T. Zhang, 2010: Changes in active layer thickness over the Qinghai-Tibetan Plateau from 1995 to 2007. J. Geophys. Res., 115, D09107, https://doi.org/10.1029/2009JD012974.

and Y. Liu, 2012: Thermal state of the active layer and permafrost along the Qinghai-Xizang (Tibet) railway from 2006 to 2010. Cryosphere, 6, 607-612, https://doi.org/10.5194/ tc-6-607-2012.

—, Y. Hou, H. Yun, and Y. Liu, 2015: Changes in active-layer thickness and near-surface permafrost between 2002 and 2012 in alpine ecosystems, Qinghai-Xizang (Tibet) Plateau, China. Global Planet. Change, 124, 149-155, https://doi.org/10.1016/ j.gloplacha.2014.09.002.

, Z. Zhang, S. Gao, and W. Ma, 2016: Thermal impacts of engineering activities and vegetation layer on permafrost in different alpine ecosystems of the Qinghai-Tibet Plateau, China. Cryosphere, 10, 1695-1706, https://doi.org/10.5194/ tc-10-1695-2016.
Wu, T., Q. Wang, L. Zhao, O. Batkhishig, and M. Watanabe, 2011: Observed trends in surface freezing/thawing index over the period 1987-2005 in Mongolia. Cold Reg. Sci. Technol., 69, 105-111, https://doi.org/10.1016/j.coldregions.2011.07.003.

Yi, S., M.-K. Woo, and M. A. Arain, 2007: Impacts of peat and vegetation on permafrost degradation under climate warming. Geophys. Res. Lett., 34, L16504, https://doi.org/10.1029/ 2007GL030550.

_ N N. Li, B. Xiang, X. Wang, B. Ye, and A. D. McGuire, 2013: Representing the effects of alpine grassland vegetation cover on the simulation of soil thermal dynamics by ecosystem models applied to the Qinghai-Tibetan Plateau. J. Geophys. Res. Biogeosci., 118, 1186-1199, https://doi.org/10.1002/ jgrg.20093.

Zhang, T., 2005: Influence of the seasonal snow cover on the ground thermal regime: An overview. Rev. Geophys., 43 , RG4002, https://doi.org/10.1029/2004RG000157.

_ , and K. Stamnes, 1998: Impact of climatic factors on the active layer and permafrost at Barrow, Alaska. Permafrost Periglac. Processes, 9, 229-246, https://doi.org/10.1002/ (SICI)1099-1530(199807/09)9:3<229::AID-PPP286>3.0.CO;2-T.

_ - T. E. Osterkamp, and K. Stamnes, 1996: Influence of the depth hoar layer of the seasonal snow cover on the ground thermal regime. Water Resour. Res., 32, 2075-2086, https:// doi.org/10.1029/96WR00996.

,$- \ldots$, and -1997 : Effects of climate on the active layer and permafrost on the North Slope of Alaska, U.S.A. Permafrost Periglac. Processes, 8, 45-67, https://doi.org/10.1002/ (SICI)1099-1530(199701)8:1<45::AID-PPP240>3.0.CO;2-K.

_ , R. G. Barry, K. Knowles, J. A. Heginbottom, and J. Brown, 1999: Statistics and characteristics of permafrost and groundice distribution in the Northern Hemisphere. Polar Geogr., 23, 132-154, https://doi.org/10.1080/10889379909377670.

,$- \ldots$, D. Gilichinsky, S. S. Bykhovets, V. A. Sorokovikov, and J. Ye, 2001: An amplified signal of climatic change in soil temperatures during the last century at Irkutsk, Russia. Climatic Change, 49, 41-76, https://doi.org/10.1023/A: 1010790203146.

_ - R. Barry, K. Knowles, F. Ling, and R. Armstrong, 2003: Distribution of seasonally and perennially frozen ground in the Northern Hemisphere. Proc. Eighth Int. Conf. on Permafrost, Zurich, Switzerland, International Permafrost Association, 1289-1294.

_ - and Coauthors, 2005: Spatial and temporal variability in active layer thickness over the Russian Arctic drainage basin. J. Geophys. Res., 110, D16101, https://doi.org/10.1029/ 2004JD005642.

Zhao, L., Q. Wu, S. S. Marchenko, and N. Sharkhuu, 2010: Thermal state of permafrost and active layer in central Asia during the International Polar Year. Permafrost Periglac. Processes, 21, 198-207, https://doi.org/10.1002/ppp.688.

Zhao, T., and A. Dai, 2015: The magnitude and causes of global drought changes in the twenty-first century under a lowmoderate emissions scenario. J. Climate, 28, 4490-4512, https://doi.org/10.1175/JCLI-D-14-00363.1. 